\title{
MeMoria de LA PRISIÓN de MUJERES de Les Corts. Un balance (2006-2014)
}

Memories of Les Corts Women's Prison. An Appraisal (2006-2014)

\section{Fernando Hernández Holgado \\ Associació per la Cultura i la Memòria de Catalunya (ACMe) - Coord. del proyecto www.presodelescorts.org}

RESUMEN: Este artículo pretende hacer un balance de la labor desarrollada por el portal web Memòria de la presó de dones de Les Corts - wwwpresodelescorts.org - presentado en 2006 en Barcelona por la Associació per la Cultura i la Memòria de Catalunya (ACMe) y todavía en activo. El texto consta de dos partes. En la primera, se describe el proyecto situándolo en el campo de la historia pública, la historia digital y la historial oral. La segunda se refiere más concretamente a las actividades realizadas durante todos estos años: desde las de difusión pedagógica — su presentación en escuelas e institutos- hasta las de participación ciudadana, con la dinamización de un proceso participativo de señalización, actualmente en marcha, que se materializaría en un futuro monumento en el antiguo solar de la cárcel, en el barrio barcelonés de Les Corts.

Palabras Clave: historia digital, historia pública, memoria democrática, historia de las mujeres, historia oral.

RESUM: Aquest article pretén fer un balanç de la tasca desenvolupada pel portal web Memòria de la presó de dones de Les Corts - www.presodelescorts.org - presentat en 2006, a Barcelona, per l'Associació per la Cultura $i$ la Memòria de Catalunya (ACMe) i encara actiu. El text consta de dues parts. La primera descriu el projecte i el situa en l'àmbit de la història pública, la història digital i la història oral. La segona es refereix més concretament a les activitats realitzades durant tots aquests anys: des de les de difusió pedagògica - presentades en escoles i instituts - fins a les de participació ciutadana, amb la dinamització d'un procés participatiu de senyalització, actualment en 
marxa, que es materialitzaria en un futur monument a l'antic solar de la presó, al barri barcelonès de Les Corts.

PaRAules CLAU: història digital, història pública, memòria democràtica, història de les dones, història oral.

ABSTRACT: This article appraises the work carried out through the website Memòria de la presó de dones de Les Corts, (memories of Les Corts women's prison) - wwwpresodelescorts.org - which was created in 2006 in Barcelona by the Associació per la Cultura i la Memòria de Catalunya (Association for Catalan Culture and Memory, ACMe) and continues to this day. The first part of the paper describes the project within the framework of public history, digital history and oral history. In the second part we explore the activities it has developed during these years, from educational dissemination in secondary schools to citizen participation activities, including a participatory process initiative that aims to erect a monument sited in the Les Corts district of Barcelona.

KEYWORDS: digital history, public history, democratic memory, women's history, oral history.

\begin{abstract}
A finales de 2006, una pequeña asociación catalana de las muchas empeñadas por aquellos años en la recuperación de la memoria histórica presentaba en Barcelona un proyecto relacionado con las nuevas tecnologías: la web Memòria de la presó de dones de Les Corts, 1939-1955 <www.presodelescorts.org $>.{ }^{1}$ Se trataba de un portal bilingüe —en castellano y catalán- dedicado a la reconstrucción-recreación de un espacio que no existía desde hacía más de treinta años: la antigua prisión provincial de mujeres de Barcelona, que durante la guerra civil había sido correccional femenino de la Generalitat. Dicha recreación se justificaba en el enunciado de presentación de la página, donde se decía que el solar que había ocupado la antigua cárcel
\end{abstract}

1. Producido por la Associació per la Cultura i la Memòria de Catalunya (ACMe). 
de Les Corts no era un «lugar de memoria» reconocido institucional y socialmente - de manera masiva-, si bien el recuerdo de la misma había logrado sobrevivir en las entrevistas y relatos de muchas de las mujeres que habían sido encerradas en sus muros. Y que era precisamente ese recuerdo el que animaba el proyecto «en la pretensión de acogerlo, fijarlo, retenerlo en un lugar de memoria no menos tangible como es la red: a modo de humilde homenaje - virtual, pero no por ello menos eficaz-a las presas de Les Corts». ${ }^{2}$

Ese «homenaje virtual» aún sigue activo, y los ochos años transcurridos desde entonces nos advierten, en primer lugar, sobre su perseverancia. Los escasos estudios existentes sobre webs dedicadas a la memoria de la guerra civil y el franquismo en España han evidenciado que la gran mayoría de las iniciativas de $\langle\text { cibercultura }\rangle^{3}$ dedicadas a la recuperación de la memoria histórica de aquella época han sido protagonizadas — bien que muchas o algunas de ellas con respaldo económico institucional - por particulares y asociaciones activistas. ${ }^{4}$ Tanto los particulares como las asociaciones — sin ánimo de lucro - de recuperación de la memoria histórica se han servido de internet - páginas estáticas, foros de opinión, blogs - como eficaces herramientas de transformación social y como una especie de «contrapoder al alcance de toda la ciudadanía» (Solanilla, 2012). Ahora bien, estas iniciativas, frente a las protagonizadas directamente por agentes institucionales y medios de comunicación - en número menor y generalmente a remolque de las primeras - se han caracterizado, como era de esperar, por una escasa estabilidad. El panorama resultante de estos ocho últimos años — buena parte de ellos de crisis económica, condicionados por cambios de gobierno y con el consiguiente cierre del grifo de las subvenciones estatales y autonómicas - ha sido el de

2. www.presodelescorts.org/es/introducció (consultado: marzo de 2015).

3. Definida como «conjunto de técnicas (materiales e intelectuales), de prácticas, de actitudes, de maneras de pensar y de valores que se desarrollan de manera conjunta en el crecimiento del ciberespacio» (Lévy, 1996).

4. Laura Solanilla estudió y analizó un corpus de 70 páginas web relacionadas con la guerra civil española, vertiendo sus conclusiones en diversos trabajos (2006 y 2012). De estas 70 páginas — foros de opinión en su mayoría, páginas estáticas, libros de visitas - 49 habían sido impulsadas por individuos (10) y asociaciones sin ánimo de lucro (39). Entre las asociaciones, destacaban principalmente las de recuperación de memoria histórica, con un carácter activista. 
la desaparición de buena parte de aquellos proyectos, disueltos para siempre en el espacio virtual.

\section{Historia digital, historia pública, historia oral}

La perspectiva de los ocho años transcurridos nos permite aquilatar mejor el desarrollo alcanzado por la web que nos ocupa a la luz de los recientes estudios de lo que se ha dado en denominar «historia digital». Si la historia digital ha sido definida como «una propuesta para el examen y representación del pasado que trabaja con las nuevas tecnologías del ordenador, de internet y de los sistemas de programario», que posibilitaría, mediante esas técnicas, «que la gente experimente, lea y siga un razonamiento sobre un problema histórico» (Vernon Burton, 2005), www.presodelescorts encajaría plenamente en esta definición. Al brindar al usuario la consulta en la página estática de un antiguo mapa de la prisión o de una antigua fotografía hecha en la misma, o de escuchar el fragmento de una entrevista realizada a una antigua presa, el proyecto no está presentando tanto un discurso cerrado - aunque la necesaria explicación general no falta - como un «conjunto de elementos interpretativos» que le permiten investigar y establecer conexiones por su cuenta (Pons, 2013). No es poca cosa esta aportación en un corpus como el español más bien escaso y pobre en este tipo de historia, sobre todo si lo comparamos con sus homólogos de otros países. ${ }^{5}$

El proyecto www.presodelescorts.org nació con una finalidad pedagógica y social: la de servirse de las nuevas tecnologías para trascender el ámbito académico y socializar el conocimiento existente sobre la que fue prisión principal femenina de la Barcelona franquista, tanto por su duración como por su población penal. Se insertaba pues también en la tradición de una «historia pública» que le permitiera corregir las lagunas existentes tanto en la historiografía como en la propia memoria pública de la ciudad, el territorio o la nación. La propia definición de «historia pública», cuya característica

5. Anaclet Pons (2013) cita sola y específicamente el espacio URBES, centrado en el estudio de las ciudades españolas $<\mathrm{http}$ ://www.urbes.unican.es/index.html $>$, así como «Ferrol. Historia Urbana», ambos de carácter universitario. 
fundamental es su «voluntad divulgadora» (Pons, 2013) y por tanto su conexión con los medios de comunicación de masas, explica el gran desarrollo que ha venido alcanzando mediante internet y las nuevas tecnologías. Según Anaclet Pons, muchas de las experiencias innovadoras del campo de la historia pública «están ligadas a las fuentes y a los archivos, a los lugares y a la memoria, a la historia local y regional, en algunas ocasiones con voluntad conmemorativa y en otros con la sencilla pretensión de profundizar en determinados hechos del pasado» (2013).

En este campo de la historia digital se encuadrarían también proyectos como Memòria i Història de Manresa <www.memoria.cat>, un portal compuesto por más de veinte webs dedicadas a distintos episodios y aspectos de la historia de esa población - investigaciones sobre los efectos de la guerra y de la represión republicana y franquista en la localidad, pero también sobre figuras de la villa como el periodista Josep Maria Planes o el escritor Joaquim Amat-Piniella, deportado en Mauthausen-. La afinidad y cercanía de la web www.presodelescorts.org con www.memoria.cat, salvando la gran magnitud de la segunda, puede reconocerse en el tratamiento de las fuentes históricas y en su digitalización: desde fotografías antiguas y documentos de archivo escaneados hasta entrevistas a testigos colgadas en la red.

El dato esencial de que la principal fuente histórica utilizada a la hora de trabajar y exponer los contenidos de www.presodelescorts.org sea la fuente oral — debidamente tratada y cotejada con otras — ${ }^{6}$ en forma de diversos clips o cortes de audio de entrevistas grabadas a testimonios que el usuario puede escuchar directamente, sitúa asimismo el proyecto en el complejo campo de la historia oral. Ello responde al singular protagonismo que se ha querido otorgar a las memorias y recuerdos de las antiguas presas, debidamente organizados por temáticas y apoyados por aparato documental: citación de las fuentes orales, biografía de la entrevistada y bibliografía de apoyo. La digitalización de las fuentes orales y su difusión en red viene constituyendo motivo de debate entre los historiadores orales desde hace años, en paralelo con el continuo desarrollo de las nuevas tecnologías. La antigua cinta magnetofónica depositada en un archivo oral que pocos usuarios consultaban

6. Sobre el tratamiento de la fuente oral, véase la metodología explicitada en la web: www.presodelescorts.org/ca/pagines/metodologia. 
puede ahora, convenientemente digitalizada y volcada en una página web, ser escuchada en formato mp3 por cualquiera y en cualquier lugar del mundo con un simple clic. E incluso ser retocada, manipulada y vuelta a reproducir en otra página, en otro medio, en una aplicación de teléfono móvil. Lo que algunos ven simplemente como enormes posibilidades de difusión y accesibilidad puede ser visto por otros - archiveros mayormente - como un peligro real: aquel al que se verían expuestos los narradores en forma de intrusiones y violaciones de su intimidad. ${ }^{7}$

En este debate actual a varias bandas - narradores, archiveros, instituciones depositarias de documentos orales-, es el celo más o menos justificado de los archivos españoles lo que parece explicar el uso casi testimonial, puramente ilustrativo por su brevedad, de las fuentes orales o audiovisuales accesibles en sus webs. ${ }^{8}$ No ha existido aquí nada parecido a proyectos como el de la vOAHa (Virtual Oral/Aural History Archive) de la Universidad del Estado de California, con más de 1000 horas de 350 narradores accesibles on line. ${ }^{9}$ Han sido más bien las aportaciones procedentes del campo de la historia pública en proyectos impulsados por asociaciones de recuperación de memoria histórica o incluso particulares las que, con mayor o menor rigor metodológico, más se han preocupado — movidos por su mayor vocación

7. Un buen resumen de esta discusión es el ofrecido por Berger Gluck, 2000.

8. Así por ejemplo, la interesante página del AHOA (Ahozko Historiaren Artxiboa, Archivo de la Memoria del País Vasco) ofrece numerosos cortes de audio de las entrevistas de las colecciones depositadas, con su respectiva transcripción, pero con una duración generalmente inferior al minuto (www.ahoaweb.org). Muchísimo menor, casi anecdótica, es la presencia de materiales orales accesibles en la Web del Seminario de Fuentes Orales de Madrid <www.seminariofuentesorales.es $>$. Una recentísima excepción a esta regla es el Banc Audiovisual de Testimonis del Memorial Democràtic de la Generalitat de Catalunya, presentado en julio de $2014<$ www. bancmemorial.gencat.cat/web/home/> que ofrece una gran cantidad de entrevistas -917 testimonios - colgadas en red.

9. Sobre las capacidades de las nuevas herramientas digitales para la difusión de entrevistas, con sus enormes posibilidades y retos, véase Frisch, 2005. El artículo más reciente de Stacey Zembrzycki (2013) nos ilumina asimismo sobre las posibilidades de softwares diseñados por y para el exclusivo uso de historiadores orales, como Stories Matter. 
divulgativa - de volcar fragmentos largos de entrevistas en formato audio o audiovisual en la red. ${ }^{10}$

El proyecto www.presodelescorts apostó desde un principio por realizar entrevistas propias a antiguas presas políticas - una minoría, ya que la mayoría de las mujeres que habían ofrecido su testimonio habían fallecido por entonces o no se encontraban en las mejores condiciones para hacerlo- pero complementándolas con la digitalización de otras ya atesoradas en los archivos, como la colección que en su momento donó Tomasa Cuevas al Arxiu Històric de la Ciutat de Barcelona (АНСВ). Fue aquí donde tropezó con las trabas impuestas a la accesibilidad como consecuencia del debate mencionado, en forma de estricta limitación del minutaje permitido: un solo clip de treinta segundos de duración. ${ }^{11}$ En las entrevistas realizadas ex novo, se pudo esquivar esa limitación a la hora de seleccionar los clips o segmentos. La opción elegida no fue, sin embargo, el volcado de entrevistas enteras - que habría resultado quizá demasiado «pesado» de escuchar - sino la selección de cortes organizados temáticamente y con una duración máxima de cinco minutos. En todo momento se pensó en el portal no como una gigantesca base de datos orales, sino como una herramienta compleja que posibilitara distintos usos de la entrevista — escuchado, lectura de la transcripción — con un fin pedagógico. El usuario podía así escuchar fragmentos más o menos largos de la voz de la narradora - con toda la riqueza de matices y de información contextual que ello suponía, más allá del texto- pero también leer al mismo

10. Algunos ejemplos son portales como el mencionado $<$ www.memoria.cat $>$ o la página del Foro por la Memoria de Málaga <www.memoriahistoricamalaga.org/index.hp>. Otras iniciativas relacionadas en mayor o menor medida con el ámbito universitario que también han apostado por el volcado de cortes largos o entrevistas enteras son el espacio digital Mujer y Memoria <www.mujerymemoria.org/Web/home/> y la página Devuélveme la voz <www.devuelvemelavoz.ua.es $>$. Especialmente interesante es el proyecto de la Fundació Pere Ardiaca sobre la militante comunista Soledad Real López $<$ www.home.soledadreal.org $>$. Omitimos aquí el enorme corpus de documentales que ha generado, por parte de particulares, asociaciones, universidades y centros de estudio, el llamado proceso de recuperación de la memoria histórica a partir de finales de la década de los noventa, buena parte de ellos accesibles en red.

11. Un solo corte oral de treinta segundos de un minuto de duración. De este minutaje fueron los materiales orales incluidos en los testimonios de Isabel Vicente y Teresa Hernández, ya fallecidas en 2003, y de Enriqueta Gallinat, que fallecería poco antes de la presentación del proyecto en 2006. Los tres se encuentran depositados en el Arxiu Històric de la Ciutat de Barcelona-Fons Orals (АHCB-FO). 
tiempo, si así lo deseaba, la trascripción completa de la entrevista entera en la misma sección. ${ }^{12}$

Visto todo lo anterior, el proyecto www.presodelescorts vino a situarse desde un principio en una encrucijada: la de la historia digital, la historia pública y la historia oral. Pero antes de seguir adelante y profundizar en su descripción y en su desarrollo durante estos ocho últimos años, conviene hacer un pequeño repaso histórico de lo que significó la prisión de mujeres de Les Corts y de lo que significaba a las alturas de 2006, inmediatamente antes de la presentación del proyecto.

\section{La prisión barcelonesa de Les Corts}

La prisión de mujeres de Les Corts, habilitada en plena guerra civil, se convirtió durante la época franquista en un almacén de reclusas, como tantos otros centros de la geografía española. Los estudios existentes sobre la misma hablan, para 1939 y 1940, de cifras de miles de presas hacinadas en un edificio con capacidad para unas doscientas. ${ }^{13} \mathrm{El}$ edificio funcionó como centro principal de la represión carcelaria femenina en Barcelona hasta 1955, y en fechas relativamente recientes fue derribado, de manera que no se conserva ningún vestigio físico del mismo. En el antiguo solar se levantaron en los años setenta unos grandes almacenes: El Corte Inglés de Diagonal. Todavía en el año 2006 no existía placa o señal alguna que recordara la existencia de la cárcel, situación que perviviría hasta el año 2010. El dato sirve para ejemplificar lo ocurrido con tantos otros espacios de represión masiva de la geografía española que sólo en tiempos muy recientes han sido reconocidos como lugares de memoria en la ciudad.

12. Algunos autores han argumentado que el uso en formato audiovisual de fragmentos de entrevistas completas en documentales periodísticos, por ejemplo, supone una descontextualización del testimonio original. Alexander Von Plato (2005) se ha preguntado así cómo serán vistos y escuchados esos fragmentos por parte de las generaciones futuras, una vez perdido, y hasta manipulado, el contexto original por medio, por ejemplo, de los fondos neutros de tantos audiovisuales.

13. Sabemos por los archivos penitenciarios que con fecha 17 de agosto de 1939, había encerradas en Les Corts 1806 mujeres y 43 niños (Hernández Holgado, 2011). 
Pese a la importancia de Les Corts para el actual proceso de recuperación de memoria histórica en nuestro país, se daba la circunstancia de que hacia finales de 2006, fecha en la que fue presentado nuestro proyecto, solamente existía un trabajo historiográfico publicado sobre la misma, el estudio pionero de Ricard Vinyes (2001). Por esas fechas se desconocía aún, por ejemplo, la lista completa de presas de Les Corts fusiladas en el Camp de la Bota durante los años 1939 y 1940. En cuanto a los testimonios diseminados en entrevistas grabadas en manos de archivos o investigadores particulares, o transcritos en libros de memorias en ocasiones de difícil localización, urgía tanto la labor de recopilación y organización de los mismos como su fijación en un soporte adecuado y su difusión en la red, socializando y democratizando todo este bagaje documental.

Cerca de ocho años después, la mirada retrospectiva que los responsables de www.presodelescorts.org podemos lanzar sobre el recorrido realizado a partir del año 2006, con las carencias mencionadas, resulta por fuerza agridulce. Ya que si por una parte son importantes los logros conseguidos en la construcción y socialización de este particular pero significativo fragmento de conocimiento histórico — de los que tratará principalmente este texto- son igualmente llamativos los vacíos. Los vacíos, sobre todo, que a lo largo de esta última década han venido dejando las ancianas que todavía a principios del siglo XXI recordaron su paso por Les Corts y nos lo contaron: Enriqueta Gallinat, que nos dejó el mismo año de 2006; Tomasa Cuevas y Soledad Real, que lo hicieron al año siguiente; Laia Berenguer, que falleció el 2011. A ellas, y a las pocas que aún sobreviven - María Salvo, Joaquina Dorado, Ángeles García-Madrid - está dedicado este artículo.

\section{Ocho años después: un balance}

Presodelescorts.org nació con un formato de espacio web que le permitía acumular una gran cantidad de información elaborada en forma de textos en 
PDF, fotografías procedentes de archivos históricos ${ }^{14} \mathrm{y}$ fragmentos orales de entrevistas de diverso origen, con un corpus original de ocho testimonios. ${ }^{15}$ Buscando precisamente la mayor difusión, la página se diseñó como bilingüe - solamente los textos de los testimonios originales están reproducidos en su idioma original, sean en catalán o en castellano - y poseía los recursos necesarios para garantizar una plena accesibilidad para personas discapacitadas, una característica lamentablemente descuidada en buena parte de las webs de memoria histórica, incluso en las que han recibido algún apoyo institucional. En otra parte se ha procedido a describir los objetivos - de investigación y pedagógicos - del portal web: ${ }^{16}$ aquí nos ocuparemos de lo que han dado de sí los ocho años transcurridos desde su presentación.

El número de visitas, que es el primer indicador al que tiene que responder un portal web, se ha mantenido en un nivel ciertamente notable para una página de contenido histórico. Durante los cinco últimos años se han contabilizado 27944 sesiones y 21607 usuarios, con una duración media de visita llamativamente alta, de 4' $09 " .{ }^{17} \mathrm{El}$ número de sesiones ha experimentado las previsibles oscilaciones en función de la publicidad ocasional del medio en noticias de prensa, radio o televisión, llegándose a alcanzar picos como el de más de un millar de visitas en septiembre de $2012 .{ }^{18}$ Durante los cuatro últimos años el porcentaje de nuevos visitantes ha alcanzado el 77'50 \%, un indicador que podría interpretarse en el sentido de que a lo largo de todo este tiempo el portal no se ha mantenido estanco, cerrado a nuevos usuarios. Del total de sesiones registradas en este último periodo, 21303, cerca de un veinte por ciento de las procedencias han sido de fuera del territorio español, con Estados Unidos y México a la cabeza.

14. Arxiu Històric Municipal del Districte de Les Corts (AHLC); Arxiu Històric de la Ciutat de Barcelona-Arxiu Fotogràfic (AHCB-AF); Fondo de la Biblioteca de la Dirección General de Instituciones Penitenciarias; y archivos personales.

15. Siete antiguas encarceladas - María Salvo, Tomasa Cuevas, Isabel Vicente, Soledad Real, Laia Berenguer, Teresa Hernández y Enriqueta Gallinat- y una hija de presa -Enriqueta Borrás.

16. Hernández Holgado, 2007 y 2008.

17. Datos de Google Analytics (consultado: 16-7-2014).

18. 1055 visitas en septiembre de 2012 y 861 al mes siguiente, con ocasión de la publicidad de actividades de muestra de cine, exposición y jornadas de debate La Presó Invisible que se comentan más adelante. 
Cifras aparte, durante estos años los esfuerzos se han repartido entre, por un lado, la ampliación de los apartados y contenidos del portal, y, por otro, las iniciativas de socialización y pedagogía dirigidas principalmente al público escolar y docente de enseñanza secundaria, pero también al ámbito vecinal, del barrio de Barcelona donde estuvo enclavada la prisión. De fundamental importancia para ello ha sido la financiación recibida por diversas instituciones: en primer lugar, tres de la Direcció General de Memoria Democràtica y del Memorial Democràtic de la Generalitat de Catalunya (2006-2009), y en segundo lugar, más reciente, la subvención otorgada por la Vicepresidencia del Gobierno del Estado en el marco de la aplicación de la Ley de Memoria Histórica aprobada en 2007 (2011-2012).

\section{a) Memorias}

Los ocho testimonios originales se han convertido en doce, con el aporte de cuatro más: dos de antiguas presas, Joaquina Dorado y Ángeles García-Madrid; y dos de familiares de presas ya fallecidas: Joan Mercadé y Albert Pueyo. Los nuevos testimonios han contado con un aparato documental más rico en forma de una mayor cantidad de fotografías e inclusión de entrevistas grabadas en video. Estos dos últimos testimonios nos han aportado una mirada sobre la cárcel que nos interesaba especialmente: la mirada infantil, la de los niños y niñas que acudían a visitar a sus familiares a la prisión. Sus biografías nos hablan asimismo de las difíciles condiciones de su desarrollo en la Barcelona franquista y de la manera, siempre cambiante, en que asumieron y elaboraron su propia memoria familiar. En las entrevistas realizadas, todas ex novo, las preguntas sobre esta particular modalidad de memoria han disfrutado de una especial atención.

El testimonio de Joan Mercadé Rius nos ha deparado una gratísima sorpresa, relacionada precisamente con esta memoria familiar. ${ }^{19}$ Por una serie de razones tan curiosas como fascinantes, a las manos de Teresa Rius, la madre de Joan que había sido encarcelada en Les Corts, había llegado a parar la carta que escribió Carme Claramunt Barot, natural de Roda de Berà pero afincada

19. www.presodelescorts.org/ca/testimonis/joan-mercadé-teresa-rius-colet. 
en Badalona, la primera presa en barcelona que fue ejecutada en abril de aquel mismo año. Se trataba de la última carta que escribió en capilla, dirigida en origen a su tieta Angelina Picas, con la que había coincidido en la cárcel. Daría mucho que comentar la historia de esta carta y de su transmisión: en el ámbito de la memoria familiar pero también de la memòria del poble, Roda de Berà, y en el seno del círculo sentimental de las antiguas compañeras de cárcel durante el franquismo. Baste señalar la emoción que hoy produce ver aquella carta de 1939, escrita en la capilla de la Prisión Modelo de hombres, reproducida con todo detalle y volcada en la red, ${ }^{20} \mathrm{e}$ imaginar su largo y difícil periplo, la amplia parábola dibujada por el tránsito de la memoria más privada a la más pública.

La intervención ha tenido asimismo un efecto beneficioso, de utilidad social, sobre la familia: el recuerdo, al socializarse y hacerse público, vindica la memoria de la persona desaparecida - Teresa Rius, Carme Claramunt_, que nunca había recibido un reconocimiento, a la par que consuela y ayuda al familiar. El camino de la socialización del recuerdo ha sido complejo: lejos de limitarse al volcado de un determinado contenido en la web, ha entrañado la realización de exposiciones, documentales y actos públicos en los que ha participado el familiar en cuestión. Se trata de un proceso complejo que merecería un artículo entero, y que ha involucrado desde colectivos de activistas - Casal Carme Claramunt de Badalona-, historiadores orales —Emili Ferrando-, ${ }^{21}$ militantes de la memoria histórica - la asociación També hi Som, de Roda de Beràhasta documentalistas, docentes y alumnos de enseñanza secundaria. Y la emoción ha tenido mucho que ver en ello: algún docente nos ha explicado alguna vez que los contenidos calan más en los alumnos si se presentan acompañados del sentimiento, vehiculados por una empatía que trasciende las épocas, abole el tiempo.

20. www.presodelescorts.org/sites/default/files/carta_carme.pdf. La carta había sido previamente reproducida por Joan Mercadé (2004).

21. Fue quien primeramente se hizo eco de la ejecución de Carme Claramunt Barot en 1939 (2000). 


\section{b) Historia}

Gracias al aporte de determinados trabajos, como el de Joan Corbalán (2008), hemos podido terminar de precisar la cifra de presas de Les Corts ejecutadas durante los años 1939 y 1940: un total de once, comprobada a partir del cotejo de fuentes penitenciarias - libro de entradas - y documentación judicial, procedente del Archivo del Tribunal Militar Territorial Tercero de Barcelona. El ajuste de la cifra ha venido acompañado de un pequeño estudio historiográfico sobre los perfiles biográficos de cada una de las ejecutadas y la mecánica de la delación, incriminación y ejecución de las mismas. ${ }^{22}$ Preciso es señalar que a lo largo de estos últimos años se ha avanzado notablemente en el conocimiento histórico de la prisión de Les Corts con la defensa y publicación de dos tesis doctorales sobre la misma: una sobre el propio centro carcelario, abarcando su primera época republicana y acabando con su cierre en 1955 (Hernández Holgado, 2011) y otra sobre la comunidad de presas políticas de las prisiones de Barcelona y Madrid durante el periodo 19391945 (Pilar Molina Javierre, 2010).

Un nuevo apartado añadido al portal - Recursos $-{ }^{23}$ nos ha permitido incorporar a manera de cajón de sastre otros contenidos de relevancia, como un pequeño estudio sobre la cárcel femenina que a principios de los sesenta tomó el relevo de Les Corts: la prisión provincial de la Trinidad (1963-1983), obra del historiador César Lorenzo. ${ }^{24}$ Este mismo apartado ha incluido entradas de temáticas diversas, pero relacionadas de alguna forma con nuestro objeto de estudio, como la de la prisión central de Adoratrices de Girona (1940-1944), ${ }^{25}$ por la que pasaron numerosas presas de Les Corts en sucesivos traslados; un estudio biográfico sobre una de las presas de la época republicana de Les Corts, la falangista Carmen Tronchoni, firmado por un descendiente suyo, Daniel Martorell Tronchoni (2008); ${ }^{26} \mathrm{y}$, en fin, una breve entrada sobre el paso de mujeres manresanas por Les Corts, a manera de ilustración

22. www.presodelescorts.org/sites/default/files/afusellades_es.pdf.

23. www.presodelescorts.org/es/recursos.

24. www.presodelescorts.org/es/node/196.

25. www.presodelescorts.org/es/node/197.

26. www.presodelescorts.org/es/node/77. 
de la mecánica — todavía por estudiar debidamente — de los traslados de presas de las diferentes cárceles de partido a la prisión provincial barcelonesa. ${ }^{27}$ Mención especial merece una de las primeras aportaciones a nuestro blog por parte de una usuaria de nuestro portal, que nos facilitó amablemente imágenes de un cuaderno escolar de una de las alumnas del antiguo colegio del Bon Consell, que posteriormente alojaría la cárcel, datado en $1889 .{ }^{28}$ Tanto el hecho de que podamos pasar hoy las páginas de aquel antiguo cuaderno en un portal de la red como el no menos importante de que lo consiguiéramos gracias a internet - fue su propietaria la que nos localizó en la red y contactó con nosotros - constituyen dos buenos ejemplos de las enormes posibilidades de las nuevas tecnologías.

Esas mismas posibilidades nos han permitido ampliar determinados contenidos, como la inclusión de las únicas imágenes cinematográficas conservadas de la prisión de Les Corts durante la época de guerra civil. ${ }^{29} \mathrm{Y}$, dentro del apartado de rescate de pequeñas joyas, cabría destacar la inclusión de dos fotografías inéditas del polígrafo nacido en Les Corts Marià Faura — sendas vistas del antiguo asilo del Bon Consell de 1914-, ${ }^{30}$ todo ello en el marco de una metodología fundamentada en la importancia de la fotografía como fuente histórica, con mayor motivo tratándose de un espacio físico ya desaparecido.

\section{c) Pedagogía}

La vertiente pedagógica de nuestro proyecto ha sido sin duda la que mayor impulso ha recibido durante estos ocho años. En primer lugar, a lo largo del 2008 encargamos a dos profesoras del Grup Historaula - Associació de Pro-

27. www.presodelescorts.org/es/recursos/manresanes-les-corts. Con enlace a una web perteneciente al portal www. memoria.cat: «La repressió franquista a Manresa en la veu de les víctimes»: www.memoria.cat/presos/ca/content/solà-sardans-anna.

28. www.presodelescorts.org/es/node/78. Nuestro agradecimiento desde aquí a Nieves Minguillón.

29. www.presodelescorts.org/es/pagines/2-brevehistoria. Cortesía de la Filmoteca de Catalunya y del Departament de Fonts Orals del Memorial Democràtic de Catalunya.

30. www.presodelescorts.org/es/pagines/3-el-edificio. Las dos fotografías, de 1914, proceden del Arxiu Fotogràfic del Museu Geològic del Seminari de Barcelona. Cortesía de Sergi Falguera Torres. 
fessorat per la Història Oral a l'Aula - la elaboración de doce fichas y unidades didácticas sobre los apartados de la web dirigidos de manera especial a alumnado de $4^{\circ}$ de ESO y Bachillerato, con diferentes niveles de complejidad. El paquete, disponible y descargable en una entrada del blog recursos, recogía también una propuesta de actividades a trabajar en tres sesiones, enfocada a la investigación de la represión franquista de las mujeres con un enfoque de género. ${ }^{31}$ Las autoras elaboraron posteriormente un artículo explicativo sobre su trabajo en la revista catalana de pedagogía Aula, así como una reseña en la Revista de la Asociación Internacional de Historia Oral (Carlota Falgueras y Maria Victòria Rubio, 2008 y 2014).

En segundo lugar, el proyecto apostó desde el principio por la producción de materiales audiovisuales sobre la historia concreta de la prisión de Les Corts por parte de jóvenes creadores, con vistas a su difusión entre, principalmente, el público escolar. Fruto de estos esfuerzos fue el documental histórico Memòria de Les Corts, veus d'una presó franquista, obra de Marc Almodóvar y Ramon Bochaca, realizado en 2008 con la participación de antiguas presas como Maria Salvo y Soledad Real, actualmente colgado en la página del proyecto. ${ }^{32} \mathrm{El}$ documental llegó a proyectarse en el programa Gran Angular de RTVE así como en la cuarta edición del Festival de Cinema en Català, celebrado en Roda de Berà (Tarragona) en junio de 2011. Más recientemente ha sido proyectado en el curso-cinefórum «El documental històric a l'aula», organizado por el CESIRE-CERES ${ }^{33}$ y el Memorial Democràtic de la Generalitat de Catalunya en febrero de 2013. En esa misma sesión, el profesor de secundaria y licenciado en Historia Ramon Breu procedió a presentar una propuesta didáctica elaborada a partir del documental Memòria de Les Corts, basada no sólo en el contenido histórico sino en el análisis del lenguaje cinematográfico, disponible también en la página. ${ }^{34}$ Asimismo hemos cola-

31. www.presodelescorts.org/ca/recursos/activitats-didàctiques.

32. www.presodelescorts.org/ca/recursos/documental-memòria-de-les-corts-veus-dunapresó-franquista.

33. Centre de Suport a la Innovació i Recerca Educativa de les Humanitats, Ciències Socials i Filosofia.

34. www.presodelescorts.org/es/node/210. Ramon Breu, fundador del portal Cinescola $<$ www.cinescola.info/ $>$ es uno de los principales impulsores del uso y del estudio del cine en la enseñanza. Véase, por ejemplo, Alba Ambròs y Ramon Breu, 2007. 
borado con otras producciones que trataban temas relacionados con nuestro objeto de estudio, caso del cortometraje documental De monstruos y faldas, de Carolina Astudillo, de 2008, que recogía testimonios de familiares de presas de Les Corts ${ }^{35}$ disponible también en nuestro portal, y que ha conocido proyecciones televisivas —el programa DOC's de Barcelona TV, en 2011 — $^{36}$ y recibido varios premios en festivales cinematográficos como el Female Eye Film de Toronto (2009) y el de Dona i Cinema de València (2011). ${ }^{37}$

En tercer lugar, y dentro de la misma línea de producción de materiales adaptados al público escolar, se apostó también por la producción de una obra teatral de pequeño formato - Silenci 39.1, en referencia a la fecha de entrada de las tropas franquistas en Barcelona, enero de 1939 - a cargo de la compañía Microtroupe sobre las vivencias de las presas de Les Corts. La obra proponía asimismo una reflexión sobre la memoria histórica en nuestros días por parte de las nuevas generaciones, y la necesidad de señalizar adecuadamente «no-lugares de memoria» como el de la antigua cárcel de mujeres. La versión entera de una de las últimas representaciones realizadas hasta la fecha - en el Centre Cívic del barrio de Les Corts, el 8 de octubre de 2012 - puede verse en un enlace del portal. ${ }^{38}$ Orientados también a un público escolar fueron los materiales de música hip hop encargados a la banda Laboca, realizados a partir de cortes sonoros de testimonios a antiguas presas y sampleados de canciones populares de la época, disponibles y descargables de manera gratuita en nuestro portal, y que fueron asimismo incorporados a la pieza teatral Silenci 39.1 como banda sonora. ${ }^{39}$

Equipados con todos estos materiales, con el formato de presentación del portal web a cargo de un historiador miembro de la asociación, la proyección del documental histórico y/o la representación de la obra de teatro, y contando siempre con el apoyo del personal docente del Grup Historaula,

35. Albert Pueyo, sobrino de Clara Pueyo; Mari Carmen Guallar, hija de Isabel Canova; Llibertat Canela, hija de Francisca Conejero; Enriqueta Borrás, hija de Rosita Mateu.

36. Programa a cuya tertulia fueron invitadas Llibertat Canela, el coordinador del programa y la autora del documental (11-11-2011).

37. www.presodelescorts.org/ca/recursos/de-monstruos-y-faldas-curtmetratgedocumental.

38. www.vimeo.com/57688985.

39. www.presodelescorts.org/ca/recursos/materials-de-música-hip-hop. 
hemos recorrido diferentes centros de Enseñanza Secundaria del área de Barcelona y alrededores. En conjunto han sido tres en $2008,{ }^{40}$ cuatro en $2012^{41}$ y uno en $2013,{ }^{42}$ con una media de 150 alumnos/as por actividad, preferentemente alumnos de $4^{\circ}$ de ESO y Bachillerato. La experiencia no ha podido ser más gratificante, y en ocasiones se ha traducido en trabajos de investigación — de obligada realización en los institutos catalanes - como «El silenci del record», realizado en 2012 por dos alumnas de un instituto al que habíamos acudido aquel mismo año, el IES Mediterrània de Castelldefels (Laia Rubio y Sara Nogales, 2011). Elaborado a partir de un uso exhaustivo de los materiales de nuestro portal, de una visita al ANC con consulta de fuentes penitenciarias y de entrevistas realizadas a familiares de presas, dicho trabajo constituye un buen ejemplo de buenas y fecundas prácticas en los estudios de Historia en Bachillerato, con especial atención a las fuentes orales. Bien asesoradas por su tutor y contando también con la ayuda de historiadores del proyecto, las alumnas han tenido un contacto directo con las fuentes documentales y, sobre todo, con los testigos. Es aquí donde la empatía y el sentimiento, aparte de transformar lo que era un trabajo académico en una inolvidable experiencia personal, intervienen decisivamente para hacer más profunda, placentera y hasta emocionante la experiencia del aprendizaje.

\section{d) Participación}

El impulso dado al proyecto durante los dos últimos años nos ha permitido vislumbrar la consecución de un objetivo largamente postergado, toda una asignatura pendiente desde que comenzó: el de trasladarlo y situarlo en el espacio físico originario, el barrio de Les Corts donde se levantaba la prisión. Entendemos que nuestro proyecto tuvo algún modesto papel en la denuncia del «no-lugar de historia» de la prisión de Les Corts, llamando la atención sobre la falta de placa o plafón alguno institucional que informara de la

40. IES Joan d'Austria, de Barcelona; IES Bernat El Ferrer, de Molins de Rei; y la Escola Intermunicipal de Sant Sadurní d'Anoia,

41. IEs Mediterrània, de Castelldefels; IEs Joan Maragall, de Barcelona; IEs Montserrat de Barcelona; y de nuevo la Escola Intermunicipal de Sant Sadurní d'Anoia.

42. IES de Roda de Berà. 
misma en el inmueble que se levanta actualmente en el solar original. A eso sirvió precisamente la llamada de atención que durante años presidía nuestro portal («Ninguna placa recuerda hoy la existencia de la antigua prisión de mujeres...»), alguna gestión con el Memorial Democràtic de la Generalitat y el Ayuntamiento de Barcelona que no llegaría a dar frutos, o la demanda recogida en diversas intervenciones nuestras tanto en el ámbito académico universitario como en revistas especializadas y medios de información, ${ }^{43} \sin$ olvidar las numerosas conferencias impartidas en diversos colectivos. ${ }^{44} \mathrm{La}$ publicación de la primera tesis doctoral sobre la prisión de Les Corts, la de Pilar Molina Javierre, editada por el Ayuntamiento de Barcelona, coincidió con una primera iniciativa de señalización municipal harto tímida y harto criticada posteriormente. La triste placa que la regidora del distrito descubrió el 1 de octubre de 2010 — previo aluvión de críticas - resultó mezquina y de difícil visibilización, colocada en un muro lateral de El Corte Inglés, cuyos propietarios intervinieron en la redacción de un texto que no recogía mención alguna a la dictadura franquista, presuntamente «para no herir susceptibilidades». ${ }^{45}$ Se trató en suma de una medida tan torpe como escasamente democrática, ejemplo de una metodología política en tanto que propagandístico-electoralista, en las antípodas de un proceso de participación vecinal. Si tuvo alguna virtud, fue la de señalar el camino que no había de seguirse, como carencia evidente de una política pública — municipal— de memoria que se pretenda mínimamente democrática o participativa.

Hacia el 2012, una última subvención institucional — la del último gobierno socialista, con lo que a partir de aquel momento se cerró el grifo de ayudas a proyectos relacionados con la memoria histórica, hasta hoy-

43. Véase por ejemplo la ponencia presentada en las jornadas de debate «La ciutat i la memòria democràtica» de la UPEC (Universitat Progresista d'Estiu de Catalunya) celebradas el 20 y 21 de noviembre de 2008 en Barcelona, y publicada al año siguiente (Hernández Holgado, 2009). En las conclusiones de las jornadas se recogió la necesidad de «señalizar el antiguo espacio de la prisión de Les Corts» (Ibidem, p. 184). La revista de divulgación histórica Sàpiens publicó también un breve artículo en un monográfico especial sobre «Espais de Memòria a Barcelona» (2010).

44. Como la celebrada en enero de 2010 en el Casal de Esquerra Republicana de Les Corts, invitados por la secretaria de formación de este partido, o la de septiembre del año anterior en el Kol.lectiu de Dones de Barberà del Vallès.

45. La historia de la triste placa, con las diversas opiniones suscitadas, está recogida en el portal: www.presodelescorts.org/ca/recursos/una-trista-placa-que-oculta-més-delque-descobreix. 
nos permitió costear una serie de actividades divulgativas dirigidas específicamente al barrio, con el título «La Presó Invisible», en colaboración con la Asociació de Veïns i Veïnes de Les Corts, el Arxiu Històric Municipal, dos centros cívicos y técnicos del mismo distrito. El formato de una muestra de cine - La Presó Invisible - nos permitió proyectar en el barrio un conjunto de documentales que conocíamos bien. A Memòria de Les Corts y De Monstruos y faldas, ya mencionados, añadimos el cortometraje inédito Executada, sobre la biografía de Carme Claramunt, la primera fusilada de Les Corts; ${ }^{46}$ Em dic Llibertat, sobre Llibertat Canela, hija de la presa Francisca Conejero; ${ }^{47}$ y En Reinserció, documental largo sobre la actual prisión de preventivas de Wad-Ras, en Barcelona. ${ }^{48}$ La presencia de las mismas directoras y de familiares de las presas en las mesas de debate generó un ambiente de complicidad que animó la participación de vecinos y vecinas. Surgieron de entre el público voces de vecinos que se acordaban de la cárcel: incluso la de algún familiar, como Flora Durán, hija de presa, que continuaba viviendo junto al antiguo solar, y a la que pudimos entrevistar posteriormente. A la creación de ese mismo clima contribuyó la representación de la obra Silenci 39.1 en el Centre Cívic de Les Corts y el montaje de una instalación artística con paneles e imágenes de la antigua cárcel que fue inaugurada en el antiguo palacete de Can Deu, transformado en centro cívico. ${ }^{49}$ Las actividades culminaron en octubre con unas jornadas de debate en las que vecinos, familiares de presas, historiadores, periodistas y arquitectos reflexionaron sobre la conveniencia de señalizar un espacio como el de la «Prisión Invisible» y sobre la mejor manera de hacerlo, y cuyas sesiones pueden visionarse enteras en la red. ${ }^{50}$

46. Un trabajo del Seminari Documental de la Universitat Raimon Llull firmado por Elisabet Cros, Guillem Sánchez y Candela Figueras, 2009. Fue su profesor, el historiador Emili Ferrando, quien les habló por primera vez de la ejecución de Carme Claramunt Barot en 1939.

47. Obra de Blanca Callén, Ester Aranda, Mireia Salgado, Mireia Cucala y Clara Farràs, de 2012 .

48. Escrito y dirigido por Pau Brunet, Isabel González y Divina López, y realizado por Jordi López. Produccions P4, 2004.

49. www.presodelescorts.org/ca/recursos/instal·lació-artística-la-presó-invisible.

50. Con tres entradas en el apartado Recursos: www.presodelescorts.org/ca/recursos. 
El mismo proceso y ambiente de debate - participación de todos y de todas - ya daba una pista sobre la respuesta a esa última pregunta.

Fruto de aquellos esfuerzos acumulados —a los que habría que añadir un nuevo montaje de la exposición La Presó Invisible en mayo de 2013 y noviembre de $2015^{51}$ y la realización de rutas por los «espacios de memoria» del barrio a cargo de la Associació Conèixer Història ${ }^{52}$ es el actual proceso de participación que se ha puesto como objetivo diseñar y proponer a las autoridades un monumento o forma de señalización digna de lo que fue la prisión de mujeres de les Corts. Desde noviembre de 2013 hasta ahora, han sido varias las reuniones realizadas para dar forma al proyecto, que han culminado en las «Jornades Internacionals i Exposició entorn al Futur Monument a la Presó de Dones de Les Corts», de noviembre de 2014, con la participación de conocidos artistas y arquitectos activistas como Fernando Sánchez Castillo, Horst Hoseisel o Francesc Torres. Dichas jornadas han enmarcado la instalación de un grupo de tótems en un lugar bien visible del barrio - esquina de la calle Europa con Joan Güell, donde se ubicaba la prisión-, y que, a la espera de conseguir un monumento definitivo, resulta un homenaje más que digno y, sobre todo, popular en cuanto fruto de un proceso de participación ciudadana. $^{53}$

Ha habido aquí sinergias importantes: la Xarxa Ciutadana de Les Corts, la Associació de Veïns i Veïnes, los miembros de Acмe y de la asociación Conèixer Història, el Projecte Dones \& Co, etcetera. Cabría destacar de manera especial el impulso dado al proyecto por el Centre de Recerca Polis de la Universitat de Barcelona, que desde hace varios años lleva invitando al alumnado del Máster de Diseño Urbano a presentar sus proyectos de señalización urbana y arte público. Uno de estos proyectos, que son los que actualmente están siendo debatidos y decididos en las reuniones de coordinación, será el que dignifique finalmente ese «no-lugar de memoria» que durante tantas décadas ha sido la prisión provincial de mujeres de Les Corts.

51. www.presodelescorts.org/ca/recursos/la-presó-invisible-torna-les-corts.

52. www.coneixerhistoria.cat/espais-barcelona/. La página de la ruta: www.rutadememoria.wordpress.com/la-ruta/.

53. Todas estas informaciones están disponibles en red: bloc.lescorts.cc/presodedones/. 
Para entonces, cuando el monumento sea finalmente una realidad, lo mejor, sin embargo, habrá quedado atrás. Los encuentros de gente diversa que han querido unirse no tanto por el deber sino por el deseo de recordar: el libre ejercicio del derecho al recuerdo y, lo que es tanto o más importante, a divulgarlo.

\section{Referencias}

Ambròs, A. y R. Breu (2007): Cinema i educació. El cinema a l'aula de primària i secundària, Graò, Barcelona.

Berger Gluck, S. (2000): «Historia oral en la Web», Historia, Antropología $y$ Fuentes Orales (HAFO), 36, pp. 5-16.

Corbalán Gil, J. (2008): Justícia, no venjança. Els executats pel franquisme a Barcelona (1939-1956), Valls, Cossetània.

Delclós, M. (2011): «Preservar, difundir, construir», La Vanguardia, Suplemento Culturas, $\mathrm{n}^{\circ} 491,16-11-2011$, pp. 3-5.

Falgueras, C. y M. V. Rubio (2008): «Una web como recurso para la investigación histórica», Aula de innovación educativa, 177, pp. 47-49. $<$ http://aula.grao.com/revistas/aula/177-la-practica-de-la-coeducacion/una-web-como-recurso-para-la-investigacion-historica $>$.

- (2014): «Oral Sources as a Pedagogical Resource. Teaching Practice and the Use of the Internet www.presodelescorts.org», IOHA (International History Association). Vol. 18.1. <http://www.iohanet.org/index. php/en/ioha-news/all-issues/4-volume-181/48-from-page-to-mouth>

Di Febo, G. (1979): Resistencia y movimiento de mujeres en España (19361976), Icaria, Barcelona.

Ferrando, E. (2000): La dona a Badalona. Cent anys de protagonismo invisible (1897-1997), Mediterrània, Barcelona.

Frisch, M. (2005): «Nuevas tecnologías de la información en la historia oral», Historia, Antropología y Fuentes Orales (HAFO), 34, pp. $149-154$.

Hernández Holgado, F. (2007): «Presodelescorts.org. Las nuevas tecnologías al servicio de la memoria y la historia de la prisión de mujeres de Les Corts (Barcelona 1939-1955)», en Amador CARretero, P. y Ruiz Franco, R. (Eds): La otra dictadura: el régimen franquista y las mujeres. Universidad Carlos III, Madrid, pp 171-181. 
- (2008): «Presodelescorts.org. Memoria e historia de la prisión de mujeres de Les Corts (Barcelona, 1939-1955)», Entelequia. Revista interdisciplinar (publicación electrónica), 7, pp. 187-196. < www. Eumed.net/entelequia/en.art.php?a $=07 \mathrm{a} 10>$

- (2009): «Memòria de la presó de dones de Les Corts», en Col·ectiu Desafectos (edit.): La ciutat i la memòria democràtica. Espais de lluita, repressió i resistència a Barcelona, BECos, Barcelona, 2009, pp. 89-98.

-(2010): «Senyalitzar la presó invisible», Sàpiens. Monográfico especial «Espais de memoria a a Barcelona», junio, p. 23.

-(2011): La Prisión Militante. Las cárceles franquistas de mujeres de Barcelona y Madrid (1939-1945), Tesis doctoral (Publicación electrónica). Universidad Complutense de Madrid. Depositado en red el 20-11-2011. URL: <http://eprints.ucm.es/13798/>

LÉvy, P. (1996): La cibercultura, el segon diluvi, Ediuoc, Barcelona.

Mangini, S. (1997): Recuerdos de la resistencia. La voz de las mujeres de la guerra civil española, Península, Barcelona.

Martorell Tronchoni, D. (2008): «Carrer de Picassent amb nom propi: Carrer de Carmen Tronchoni», Festes Majors Picassent 2008, Ajuntament de Picassent, pp. 20-33.

Mercadé Rius, J. (2004): «Un testimoni humà per a la reflexió», BOI. Roda de Berà. Les Monges Associació Cultural, 12, pp. 16-21.

Molina Javierre, P. (2010): La Presó de Dones de Barcelona. Les Corts (1939-1959), Ajuntament de Barcelona, Barcelona.

Von Plato, A. (2005): «¿Qué pasa con la experiencia en el proceso de transición de la historia contemporánea a la historia pura?», Historia, Antropología y Fuentes Orales (HAFO), 33, pp. 49-52.

Pons, A. (2013): El desorden digital. Guía para historiadores y humanistas, Siglo XXI, Madrid.

Romeu, F. (1994): El silencio roto. Mujeres contra el Franquismo, Autoedición, Madrid. Reeditado en 2002 (Barcelona, El Viejo Topo).

Rubio, L. y S. Nogales (2013): «El Silenci del Record. Presó de dones de Les Corts de Barcelona», de Laia Rubio y Sara Nogales. <www. presodelescorts.org/ca/recursos/un-treball-exemplar-de-recerca-el-silenci-del-record $>$

Solanilla, L. (2006): «Digitalitzant el record. La memòria de la guerra civil española en internet», L'Avenç. Revista de història y cultura, 314, Barcelona, pp. 36-40. 
- (2012): «Sociologando: Internet como herramienta de recuperación de la memoria de la Guerra Civil Española», Boletín Científico Sapiens Research, Vol.2 (2), pp. 46-52. <www.dialnet.unirioja.es/descarga/ articulo/3973511.pdf>

Vernon Burton, O. (2005): «American Digital History», Social Science Computer Review, Vol. 23, n 2, 2005.

VINYES, R. (2001): «Nada os pertenece... Las presas de Barcelona, 19391945», Revista de Historia Social, 39, València, pp. 49-66.

Zembrizcki, S. (2013): «Bringing Stories to Life: Using New Media to Disseminate and Critically Engage with Oral History Interviews», Oral History, primavera de 2013, pp. 98-107. 
